IRA-International Journal of Management \& Social Sciences

ISSN 2455-2267; Vol.03, Issue 03 (2016)

Institute of Research Advances

http://research-advances.org/index.php/RAJMSS

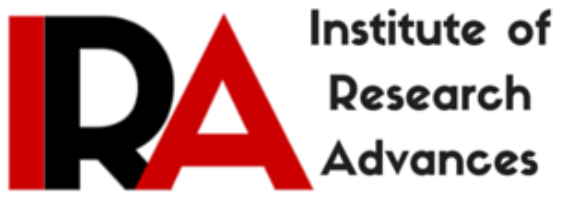

\title{
Swadhyaya: A Cognitive Therapy for Hostility
}

Dr. Reena Bajpai

Assistant Professor (Dept. of Clinical Psychology)

Dev Sanskriti Vishwavidyalaya, Shantikunj, Haridwar (U.K.), India.

DOI: http://dx.doi.org/10.21013/jmss.v3.n3.p8

\section{How to cite this paper:}

Bajpai, D. (2016). Swadhyaya: A Cognitive Therapy for Hostility. IRAInternational Journal of Management \& Social Sciences (ISSN 2455-2267), 3(3). doi:http://dx.doi.org/10.21013/jmss.v3.n3.p8

(C) Institute of Research Advances

\section{(cc) BY-NC}

This works is licensed under a Creative Commons Attribution-Non Commercial 4.0 International License subject to proper citation to the publication source of the work.

Disclaimer: The scholarly papers as reviewed and published by the Institute of Research Advances (IRA) are the views and opinions of their respective authors and are not the views or opinions of the IRA. The IRA disclaims of any harm or loss caused due to the published content to any party. 


\section{ABSTRACT}

Purpose: Swadhayaya is pondering over good thoughts that links our minds with the knowledge of saints and sages and thus enlightens and re-orients our own thoughts consequently. Hence the aim of this research was to see the effect of Swadhyaya on Hostility.

Scope: Swadhyaya is a great psycho-spiritual intervention, which, if inculcated in the routine life of adolescent girls, can do their cognitive restructuring, which in turn can alleviate hostility.

\section{Research Methods:}

a) Sample and Sampling: 14 to 18 years old, 40 subjects were selected with the help of simple random sampling.

b) Research Design: Randomized two group design was applied to present research work.

c) Tool: For the assessment of hostility an Indian Modification of the Thematic Apperception Test (T.A.T.) Developed by Uma Chowdhury was applied.

d) Statistical Analysis: Statistical analysis was done through MS-Excel software by using .two-samples assuming equal variances.

e) Result: The results showed significant changes on the basis of which it can be said that swadhyaya as a therapy can be extremely helpful for balancing hostility of the adolescent girls.

Key words: Swadhyaya, Hostility, Girl's health, process, utility of swadhyaya, Thematic Apperception Test

\section{Introduction}

Hostility is a broad concept. It is associated with anger, aggressive behavior, suspicion, mistrust, a desire to oppose others and a wish to harm others. There is a distinction between the experience of hostility and its expression. The experience of hostility is subjective because it includes angry feelings, suspiciousness, mistrust, a desire to oppose others and a wish to harm others. The expressive hostility implies the acts which are observable, such as aggression, which may be verbal (for example, insulting someone) or physical (for example, punching someone) (Whiteman, Fowkes, Deary, \& Lee, 1997a). In an average level hostility is beneficial for survival- it is essential for endurance, but in increased level it produces neurosis, criminality, war and social conflict. Rage, Anger, cruelty, violence, aggressive behavior, and similar destructive impulses can be included under the term hostility. A strong relationship has been found between hostility and aggression; those people who perceive more hostility show more aggressive behavior than others (Orobio de Castro, Veerman, Koops, Bosch, \& Monshouwer, 2002).

Hostile individual is resentful, hot-headed, shows displeasure, impulsive reaction, shout angrily, gets mad when caught, slow to cool off, defensive, grouchy. Russel and Fehr, 1994 (as cited in Haukkala, 2002a) summarize that anger is said to be a subcategory of hostility or vice versa, while some researchers argue that they are, in fact, identical. 
However, in the field of health psychology there are three components of hostility; the cognitive component consists of negative beliefs about others, the affective component includes emotional states, like anger, while aggression is an example of the behavioral component of hostility (Smith, 1994 as cited in Haukkala, 2002b).

\section{Hostility and Health}

Health psychologists have devoted their concentration to the construct of hostility because of its apparent involvement with disease outcomes (Miller, Smith, Turner, Guijarro, \& Hallet, 1996a). They made a great effort in examining the psychophysiological processes of hostility which establishes a relationship between hostility and disease outcomes (Smith, 1992) and the psychological and social variables with which it is linked. Hostility has been associated with many health problems and diseases (Grano, Vahtera, Virtanen, Keltikangas-Jarvinen, \& Kivimaki, 2008). From different researches it has been proved that there are three different mechanisms through which hostility affects a person's health. First is behavioral approach which explains that hostile people are engaged in heavy drinking, smoking and sedentary life style (Whiteman, Fowkes, Deary, \& Lee, 1997b). Second, psycho-physiological approach explains that hostility has a bad effect on health through sympathetic reactions (Miller, Smith, Turner, Guijarro, \& Hallet, 1996b). Third, psychosocial vulnerability approach explains that hostile people have very small social networks; they receive very less social support (Smith, 1992).

Kurylo and Gallant (2000) told that "Hostility has been inconsistently related to cardiovascular reactivity in studies of Women." They examined college-age women's relation of hostility with cardiovascular reactivity and mood, during self-disclosure of a distressing event to an unknown man. In result they found that Women in the selfdisclosure condition, had greater systolic blood pressure, anxiety, and depressed mood than participants in the non-disclosure condition, independent of their level of hostility. Hostile women during self-disclosure condition, reported greater anger in post experiment than women in the other three groups, and anger was related to diastolic blood pressure. Anxiety and depressed mood were related to systolic blood pressure and diastolic blood pressure for low hostile women in the self-disclosure condition. Results suggest an interrelation of hostility with negative mood and reactivity.

Piferi, and Lawler (2000) in a research explored the relationship between hostility and women's health, they examined the association of hostility to cardiovascular reactivity during stressful, interpersonal confrontations. First of all, each participant's level of hostility, methods of coping with stress, and perceived social support were evaluated. Blood pressure and heart rate were also examined in 90 females during two discussions with a disagreeing colleague. In first discussion, concerning the performance, participants were given positive feedback, while in a second discussion; concerning the effectiveness in expressing their viewpoints, participants were given non-positive feedback. The results indicated that, during the discussions, low hostile women displayed greater systolic blood pressure, and heart rate increased than high hostile women. In addition, during the positive feedback condition, the participants exhibited greater systolic blood pressure and diastolic blood pressure reactivity, than during the nonpositive feedback condition. On the other hand, for diastolic blood pressure, these results were qualified by an interaction, such that during the positive feedback condition, low hostile women displayed greater reactivity than during the non-positive feedback condition, whereas high hostile women were equally reactive in both feedback conditions. State assessment of coping styles indicated that, high hostile women may be less reactive because of withdrawal and lack of engagement during the task, whereas low hostile women may show greater engagement, especially when encouraged by positive feedback. 


\section{Girls' Hostility}

According to some investigators believe that boys may appear much more aggressive than girls because they focused on overt aggressive behaviors and have failed to think upon covert hostile acts that may be more common among girls than boys (Shaffer \& Kipp, 2010a). Crick and Grotpete, 1995 study (as cited in Shaffer and Kipp, 2010b) boys display hostility in overt forms of aggression towards others who displease them or those who interfere with achieving goals. On the other hand the girls pursue, covert forms of relational aggression-actions such as withdrawing acceptance from an adversary, excluding themselves from one's social network, or taking some sort of action (e.g. Spreading rumors) that might damage their friendships or general status in the peer group.

\section{Swadhyaya}

In present time environment has very bad effect on human beings life. It does not encourage us towards positivity. Instead, it inculcates in us negative tendencies, sensual passions, selfishness and hostility. If we want to excel ourselves from negativity to positivity, if we want to cross the barriers of present circumstances and want to excel in righteous sense, we shall have to do extra efforts. These extra efforts may be in the form of swadhyaya. In swadhyaya we link our mind with the knowledge of saints and sages and try to re-orient our mind accordingly.

In this quest of the unknown, seeking a major breakthrough in this worldly vision many renowned scientists have started looking at the finding in the East for new insights. There are many Indian techniques swadhyaya is one of the best among them.

Swadhyaya is divided into two words: Swa means self (one's own) adhyaya means study so the factual meaning of Swadhyaya is self-study (Sturgess, 2004). Under swadhyaya we deal with ourselves (our thoughts, aspirations, attitudes and behavior) in context of thoughts of enlightened personalities.

Swadhyaya is the study of spiritual books, which are the stories of saints, the teachings of enlightened sages, philosophical works etc. (Chidananda, 1991). Swadhyaya is not mere reading. Swadhyaya is a deliberate study, with attention to the meaning, of what one is studying, so that one is actually absorbed in what is being studied. Therefore, there is every day a fresh intake of spiritual ideas into the mind, into the consciousness. These spiritual ideas are not only informative, but also inspirational, as well as of a transforming nature in their effect upon the mind. Swadhyaya means the study with attention on the meaning with the specific purpose of taking in and absorbing it. The continuous practice of our own life is also a Swadhyaya (Goyandka, 2006). In Swadhyaya, we select a small portion of good literature, read it, understand its implications, do contemplation over its teachings or guidance and adopt it in our behavior.

Vyas told about Swadhyaya

Swadhyayo mokshshastranamdhyayanam pranavajapo va (vyas bhasya 2/32, 2/1)

I.e. Study of Moksh shastras and also the recitation of OM mantra are Swadhyaya.

\section{Process of Swadhyaya}

Pandya (2005a) told that Swadhyaya is the great process of micro study of our cognition. There are mainly four steps in Swadhyaya:

\section{a) Selection of good inspirational literature:}

For swadhyaya firstly the aspirant selects those kinds of classics and literature, which were created by people who had realized their own selves e.g. Vedas, Upnishads, ShimadbhagwadGeeta, Ramcharitmanas, books written by great philosopher and saint 
Pt. Shri Ram Sharma 'Acharya', Shri Aurobindo, Swami Vivekananda etc. and Biographies of great yogis.

\section{b) Self Evaluation}

In the second step, we analyze ourselves in context of these thoughts and try to compare our mental state with respect to these thoughts. We also try to understand the method to develop our mental state and evaluate what we are doing and what we should be thinking and what we should be doing.

c) Make a strategy to rectify the thoughts

In the third step, we make a strategy to rectify our thoughts, emotions, believes, faiths, insistences, recognitions. We make a complete plan for removing our obstacles and working process for this plan is also determined.

\section{d) Adopting in behavior}

In the fourth and last step, the new thoughts received from Swadhyaya are adopted in our behavior completely, because without bringing these thoughts in our behavior, all these efforts shall be useless.

\section{Utility of Swadhyaya}

Svadhyayad-ishta-devata samprayogah (Patanjala yoga Sutra 2/44)

I.e. From Swadhyaya aspirant got communion with the deity.

\section{Swadhyayadyogmaseet yogatswadhyaymamnet}

\section{Swadhyayyogsampattya parmatma prakashte (vyas bhasya $1 / 28$ )}

\section{I.e. From Swadhyaya and Yogabhyasa aspirant get communion with the deity.}

The great father of India Mahatma Gandhi told that swadhyaya in our personality is like that window, from which higher level motivations come like a fresh air and which fills us with freshness of thoughts and feelings (Pandya, 2006). Swadhyaya is a great method of purifying the mind and righteous molding of the thoughts and attitude. With the daily intake of spiritual ideas, the process of mind transformation occurs. One that can take away all our worries, can solve all our problems and doubts, and arouse the feeling of well-being for everyone, only that can be a true Swadhyaya (Brahmavarchas, 1998).The old mind is eliminated gradually. The thoughts related to hostility, ignorance and non-awareness are pushed out gradually and a new mind is created within us, which in its full awareness thinks spiritually with its full enlightened wisdom. Swadhyaya changes the flow of our entire life in a positive spiritual direction, in an upward ascending dimension.

Keeping these views in mind, researchers decided to see the effect of Swadhyaya on hostility of adolesvent girls. For assessing it the researcher formulated research hypothesis:

"Swadhyaya practicing and non practicing groups have significant difference in the level of Hostility". 


\section{Research Methodology}

\section{a) Participants:}

In study, researcher recruited 14-18 years old 40 girls from 150 girls through simple random sampling from Rajkeeya Mahila Inter College, Haridwar, Utarakhand. For randomization researcher applied Lottery method.

\section{b) Tool:}

To assess hostility, an Indian Modification of the Thematic Apperception Test (T.A.T.) of Murray by Uma Chowdhury was applied. Thematic Apperception Test is a very well known and widely used projective test. Five TAT cards having relevance with hostility, anger and aggression were administered on the subjects after giving proper instructions. The choice of specific cards was based on the characteristics of the stimuli and the ability to elicit hostility. For it card T (2), T (3FG),T(4FG), T(5) and T(6) were administered on the participants.

\section{c) Scoring:}

Scoring was done with the help of TAT Manual developed by Dr. L.P.Mehrotra. The slightest suggestion of a variable is given mark 1, whereas intense form or the continued occurrence or repeated occurrence of a milder form is scored 5 , marks of $2,3 \&$ 4 are given accordingly for intermediate intensities of expression.

\section{d) Design and Procedure:}

The study used a randomized- two group design. The procedure of the study was that the researcher selected a room where she gave some spiritual and motivational literature to students for study and discussion. Highlighting the necessity of good literature, Sysaro has mentioned at one place-"Reading good literature is a source of mental nourishment for the youth and entertainment and happiness for the old; it opens up the doors of hope and gives patience and courage in moments of difficulty. Literature keeps hearty inside one's home and humble outside...." (Pandya, 2003). Participants did Swadhyaya of Srimad Bhagvad Geeta's second chapter, some inspiring spiritual books like Hariye na himmat and story books written by Pt. Shri Ram Sharma Acharya, for forty five days and 30 minutes daily. Every day they read one paragraph and discussed what inspiration they got from it.

\section{e) Statistical Analysis:}

Statistical analysis was done through MS-Excel software by using two-samples assuming equal variances.

\section{Result}

The post means of Swadhyaya practicing group and Non practicing group were 6.5 and 8.15 ., SD were 2.50 and 2.76 and $t$ value was 1.98 . which was significant at .10 level of confidence. So the result shows that regular practice of Swadhyaya decreases the level of Hostility in practicing group as compare to not practicing group in post test. So research Hypothesis "Swadhyaya Practicing and non practicing groups have significant 
difference in the level of Hostility" has been accepted at .10 level of confidence. Therefore, it can be concluded that regular practice of Swadhyaya decreases the level of Hostility in practicing group.

\section{Discussion}

The research hypothesis "Swadhyaya Practicing and non practicing groups have significant difference in the level of Hostility" has been accepted at.10 level of confidence, because, at 38 degrees of freedom obtained value of t test was more than given value at. 10 confidence level.

As a human being we suffer from a loss of self awareness, a wrong identification with prakriti in the form of body and mind and also with this physical world because of our ignorance. The regular practice of swadhyaya develops in us the real awareness; it removes the obstacles of mind and develops the ability to discriminate between the real and unreal. Swadhyaya creates in us a permanent type of background of thought of the right quality, of the spiritual quality. In spiritual world, Swadhyaya works as a therapy and works on the principle of replacement of negative thoughts by positive ones (Sao, Bharadwaj \& Agrawal, 2013a).

Negative thoughts such as hostility, pessimistic attitudes etc. always attack to our mind like viruses. With the help of swadhyaya, we can protect our mind from these kinds of viruses. Like a powerful scanner swadhyaya scans the hostile attitude from the mind and replaces there the positive thoughts that make our mind illuminated (Sao, Bharadwaj \& Agrawal, 2013 b). Hence there is nothing better than swadhyaya for keeping our cognition immune from all the mental afflictions (Pandya, 2005b). So now it is clear that swadhyaya is very beneficial in decreasing the level of hostility among adolescent girls.

\section{Acknowledgment}

I am very thankful to the principal and teachers of Rajkeeya Mahila Inter College, Jwalapur, Haridwar (U.K), that they permitted, and provided me all facilities so that I could do data collection. I am also thankful to the students for their cooperation, sincerity, punctuality and interest.

\section{References}

- Brahmavarchas (1998). Aatmotkarsha ka aadhar gyan.Akhand Jyoti Sansthan, Mathura, $\mathrm{p} 45$.

- Chidananda, S. (1991). Right application in yoga brings success. Lectures on Raja Yoga. A divine life society publication.

- Goyandka, H. (2006). Maharshi Patanjali krit yoga darshan. Geeta press, Gorakhpur, India, p, 33.

- Grano, N., Vahtera, J., Virtanen, M., Keltikangas-Jarvinen, L., \& Kivimaki, M. (2008) .Association of Hostility with Sleep Duration and Sleep Disturbances in an Employee Population. International Journal of Behavioral Medicine, 15: 2, 73 $-80$ 
- Haukkala, A. (2002ab). Socio-economic Differences in Hostility Measures - a Population Based Study. Psychology \& Health, 17: 2, 191- 202. DOI: 10.1080/08870440290013671.

- Kurylo, M., \& Gallant, S. (2000). Hostility and Cardiovascular Reactivity in Women During Self-Disclosure. International Journal of Behavioral Medicine, 7: 3, $271-285$.

- $\quad$ Miller, T. Q., Smith, T.W., Turner, C.W., Guijarro, M. L., \& Hallet,A. J. (1996ab). A meta-analytic review of research on hostility and physical health. Psychological Bulletin, 119, 322-348.

- Orobio de Castro, B., Veerman, J. W., Koops, W., Bosch, J. D., \& Monshouwer, H. J. (2002). Hostile attribution of intent and aggressive behavior: A metaanalysis. Child Development, 73, 916-934.

- Pandya, P. (2006).Swadhyaya-Satsang dainik jeevan ka ang bane. Akhand Jyoti, Akhand Jyoti Sansthan Mathura, 70 (9), 49.

- Pandya, P. (March, 2005 a,b).Man aur jeevan ki chikitsa karta hai swadhyaya. Akhand Jyoti, Akhand Jyoti Sansthan Mathura, 69 (3), 11-12.

- Pandya, P. (july-Aug. 2003). Importance of good literature for enlightened power and progress. Akhand Jyoti, Akhand Jyoti Sansthan, Mathura, 1(4), 35.

- Piferi, R.L. \& Lawler, K. A. (2000). Hostility and the Cardiovascular Reactivity of Women during Interpersonal Confrontation. Women \& Health, 30: 3, 111 129. DOI: $10.1300 / J 013 v 30 n 03 \_08$

- Sao,H.K., Bharadwaj,A.K. \& Agrawal, G.(2013ab), A model of swadhyaya chikitsa for healthy mind and cognitive restructuring. Dev Sanskriti: Interdisciplinary International Journal, 2, 62-66.

- Shaffer, D.R. \& Kipp, K. (2010ab). Aggression, Altruism and Moral development. Developmental psychology: Childhood \&adolescence. Wadsworth Cengage Learning, p568.

- Smith, T. W. (1992). Hostility and health: Current status of a psychosomatic hypothesis. Health Psychology, 11, 139-150.

- Smith, T.W. (1992). Hostility and health: current status of a psychosomatic hypothesis. Health Psychology, 11, 139-150.

- Sturgess S. (2004).Niyamas. The Yoga book. Motilal banarsidas publishers,Delhi:62-126.

- Whiteman, M. C., Fowkes, F. G., Deary, I. J., \& Lee, A. J. (1997ab). Hostility, cigarette smoking and alcohol consumption in the general population. Social Sciences and Medicine, 44, 1089-1096. 
Result table- Table showing post and post analysis of Swadhyaya practicing and non practicing groups through independent samples $t$ test

\begin{tabular}{|l|l|l|l|l|l|l|l|}
\hline Group & & $\mathrm{N}$ & $\mathrm{M}$ & $\mathrm{SD}$ & $\mathrm{SE}_{\mathrm{D}}$ & $\mathrm{t}$ value & Significance level \\
\hline $\begin{array}{l}\text { Swadhyaya } \\
\text { practicing } \\
\text { group }\end{array}$ & Pre & 20 & 8.65 & 2.18 & & & \\
\cline { 2 - 5 } & Post & 20 & 6.5 & 2.50 & \multirow{2}{*}{0.83} & \multirow{2}{*}{1.98} & $\mathrm{P}<.10$ \\
\cline { 1 - 5 } $\begin{array}{l}\text { Not practicing } \\
\text { group }\end{array}$ & Pre & 20 & 8.10 & 2.53 & & & \\
\cline { 2 - 5 } & Post & 20 & 8.15 & 2.76 & & & \\
\hline
\end{tabular}

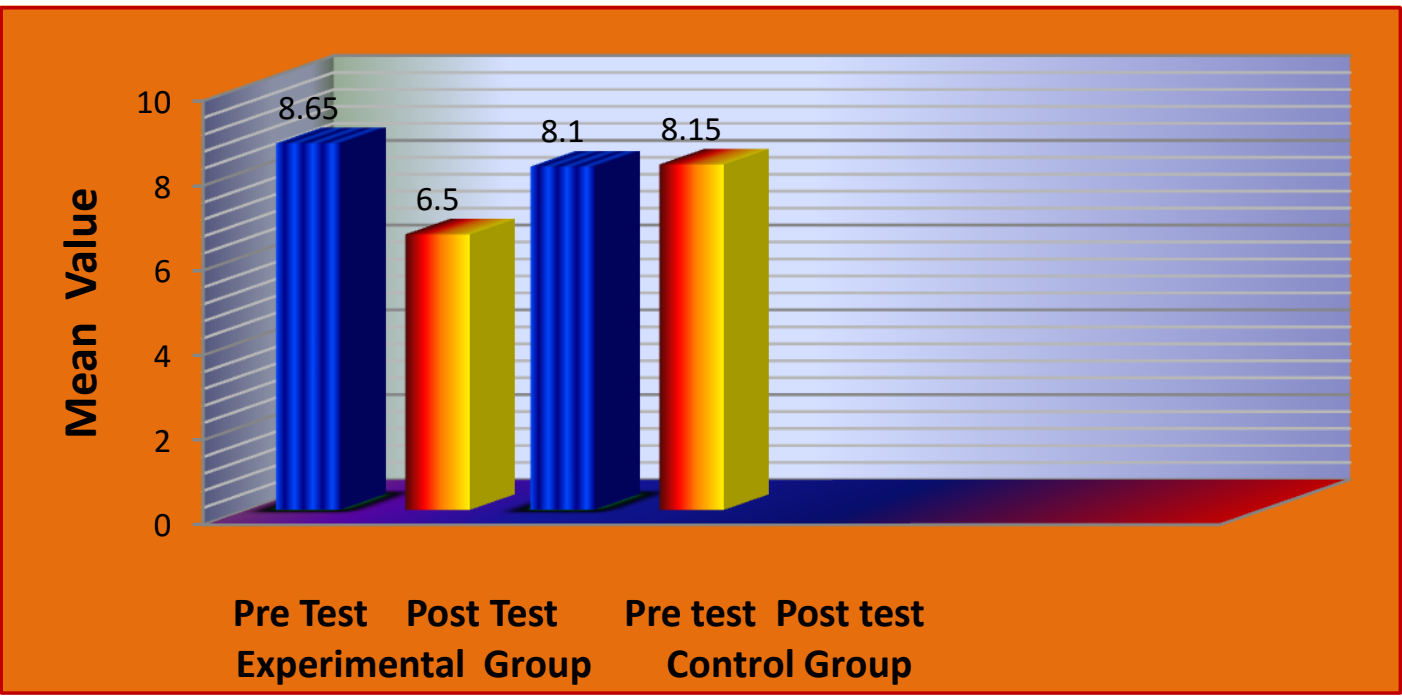

\section{Brief Professional Biography of Author:}

Name: Dr. Reena Bajpai

Education: MSc in Clinical Psychology, PhD, UGC-NET (Psychology)

Designation: Assistant Professor (Dept. of Clinical Psychology)

Affiliation: Dev Sanskriti Vishwavidyalaya, Shantikunj, Haridwar (U.K.), India. Teaching experience: Eight years

Research paper Publication: six papers published in different national, international journals and books.

Seminars /Conferences: Fifteen papers are presented in different national seminars

Best paper award: Two best paper awards 